\title{
Extreme Value Analysis of Metocean Data for Barents Sea
}

\author{
Sung Boo Park ${ }^{\circledR 1}$, Seong Yun Shin ${ }^{\circledR 1}$, Da Gyun Shin ${ }^{\circledR 1}$, Kwang Hyo Jung ${ }^{\oplus^{2}}$, \\ Yong Ho Choi ${ }^{{ }^{3}}$, Jaeyong Lee ${ }^{{ }^{4}}$ and Seung Jae Lee $\oplus^{5}$ \\ ${ }^{1}$ Graduate student, Department of Naval Architecture and Ocean Engineering, Pusan National University, Busan, Korea \\ ${ }^{2}$ Professor, Department of Naval Architecture and Ocean Engineering, Pusan National University, Busan, Korea \\ ${ }^{3}$ Principal Researcher, Ship and Offshore Research Center, Samsung Heary Industries, Co. Ltd, Daejeon, Korea \\ ${ }^{4}$ Professor, Department of Naval Architecture and Ocean Engineering, Dong-Eui University, Busan, Korea \\ ${ }^{5}$ Professor, Division of Naval Architecture and Ocean Systems Engineering, Korea Maritime and Ocean University, Busan, Korea
}

KEY WORDS: Extreme value analysis, Metocean data, Significant wave height, Spectral peak wave period, I-FORM, Gumbel distribution, Weibull distribution, Log-normal distribution

\begin{abstract}
An extreme value analysis of metocean data which include wave, wind, and current data is a prerequisite for the operation and survival of offshore structures. The purpose of this study was to provide information about the return wave, wind, and current values for the Barents Sea using extreme value analysis. Hindcast datasets of the Global Reanalysis of Ocean Waves 2012 (GROW2012) for a waves, winds and currents were obtained from the Oceanweather Inc. The Gumbel distribution, 2 and 3 parameters Weibull distributions and log-normal distribution were used for the extreme value analysis. The least square method was used to estimate the parameters for the extreme value distribution. The return values, including the significant wave height, spectral peak wave period, wind speed and current speed at surface, were calculated and it will be utilized to design offshore structures to be operated in the Barents Sea.
\end{abstract}

\section{Introduction}

According to the National Oceanic and Atmospheric Administration (NOAA), the Earth's average temperature is increasing annually as global warming continues, and the temperature of the Arctic region is increasing twice as fast as those of other regions (NOAA, 2018). With Arctic glaciers melting owing to global warming, the importance of developing marine resources buried in the Arctic is emerging. According to the United States Geological Survey, undiscovered recoverable resources in the Arctic region include approximately 90 billion barrels (Bbbl) of oil, 1,669 trillion cubic feet (Tcf) of gas, and $44 \mathrm{Bbbl}$ of natural gas liquid (Bird et al., 2008). It is estimated that $13 \%$ of the world's undiscovered oil volume and $30 \%$ of the world's undiscovered gas volume are buried in the Arctic region. In general, marine resources in the deep sea are developed by offshore structures, and it is important to collect and analyze the metocean data of sea areas where marine resources are buried for the operation and survival of offshore structures. Metocean data include wave, wind, current, water depth, tide, and soil conditions. To reflect metocean data in the design of offshore structures, extreme value analysis should be conducted (API, 2005). Metocean data can be collected from measurement data of actual sea areas that use buoys or ships, hindcast data that estimate the desired data of the past through numerical methods based on past metocean data, and satellite data that use satellites. According to DNVGL (2015), for the design of offshore structures, the significant wave height $(H s)$ and spectral peak wave period $(T p)$ of 100-year return values should be used for waves, whereas the 100-year return value of the one-hour average wind speed at $10 \mathrm{~m}$ above the mean sea level (MSL) should be used for wind speed. For ocean currents, the 10 -year return value of the current speed should be reflected in the design.

To derive return values through statistical methods, methods for selecting the collected data must be determined. Such methods can be primarily categorized into global and event models. Global models include the initial distribution and total sample methods that use the entire data statistically, and the event models include the peak over threshold method, which uses data above a certain threshold, and the annual maxim method, which uses only the annual maximum values (DNV, 2014).

Extreme value distributions (EVDs) used for extreme value analyses include the Gumbel, Frechet, Weibull, and log-normal distributions. Methods for estimating the parameters of EVDs include

Received 15 October 2019, revised 28 January 2020, accepted 14 February 2020

Corresponding author Kwang Hyo Jung: +82-51-510-2343, kjung@pusan.ac.kr

(c) 2020, The Korean Society of Ocean Engineers

This is an open access article distributed under the terms of the creative commons attribution non-commercial license (http://creativecommons.org/licenses/by-nc/4.0) which permits unrestricted non-commercial use, distribution, and reproduction in any medium, provided the original work is properly cited. 
the method of moment, maximum likelihood estimation, and least-squares method (DNV, 2014). Jeong et al. (2004) conducted extreme value analyses using Weibull, Gumbel, Log-Pearson type-III, and log-normal distributions using the $H s$ data of approximately 20 years obtained from 67 ocean stations in South Korea. They provided design wave height information in the deep-sea for the return period of 50 years and suggested that Gumbel distribution was the most suitable method. In addition, they provided the extreme highest tide level information for each return period by conducting an extreme value analysis through generalized extreme value, Gumbel, and Weibull distributions using the extreme highest tide level data of 23 tide stations on the coast of South Korea, and they suggested that Gumbel distribution was the most suitable method (Jeong et al., 2008). Ko et al. (2014) developed a numerical wind speed model that numerically implemented typhoons for four locations on the west coast of the Korean Peninsula (Gunsan, Mokpo, Jeju, and Haemosu No. 1) and presented extreme wind speeds for the four locations by applying the Gumbel distribution and estimating parameters through the probability weighted moment method.

EVDs were applied to various metocean data. In the case of wave data, however, $H s$ and $T p$ were important design elements for the design of offshore structures. DNVGL (2017) and BV (2015) recommended the use of the inversed first order reliability method (I-FORM), which used the joint distribution of EVDs, to obtain the return values for $H s$ and $T p$.

In this study, the metocean data (wave, wind, and current) of the Barents Sea in the Arctic region were collected. In addition, for the extreme value analysis of the wave data, return values were calculated using I-FORM, which used the joint distribution of the marginal probability distribution for $H s$ (Gumbel distribution and two- and three-parameter Weibull distributions) and the conditional probability distribution of $T p$ for the given $H s$ (log-normal distribution) (DNVGL, 2017; BV, 2015; Choi, 2016). For the wind and current speeds, which are single variables, extreme value analysis was conducted through the Gumbel distribution and two- and three-parameter Weibull distributions. The least-squares method was used for parameter estimation, and the Kolmogorov-Smirnov (K-S) test was applied as the goodness-of-fit test. Through these processes, the return values for $H s$, $T p$, wind speed, and current speed required for the design of offshore structures to be operated in the Barents Sea were derived.

\section{Metocean Data Collection and Analysis}

The project site (Fig. 1) is the Barents Sea of water depth $258 \mathrm{~m}$ (latitude: $73 \mathrm{~N}$ and longitude: 44E), where gas fields were distributed around the site (Fig. 2). For the wave (Hs, $T p$, and wave direction), wind (wind speed and wind direction), current (current speed and current direction), and an ice floe thickness data, the hindcast datasets of Global Reanalysis of Ocean Waves 2012 (GROW2012) from Oceanweather Inc. were purchased. In the hindcast datasets of GROW2012, wave and wind models provided by the General
Bathymetric Chart of the Oceans and Climate Forecast System Reanalysis were used to estimate the data for waves, wind, current, and ice floe (Oceanweather Inc.).

To conduct the extreme value analysis, the consistency, period, and validity of the collected data must be examined first (Van Os et al., 2011). Compared with the measurement data, the hindcast data have no possibility of missing data and generating outliers owing to typhoons or defects in the measuring equipment and can secure a data period irrespective of the installation time of the measuring equipment. The wave and wind data were recorded at one hour intervals for a decade from January 2007 to December 2016, and the current data were recorded in the water depth direction at one day intervals for two decades from January 1993 to December 2012. The ice floe thickness data during the same period as that of the current data were provided, but it was discovered that no ice existed in the project site.

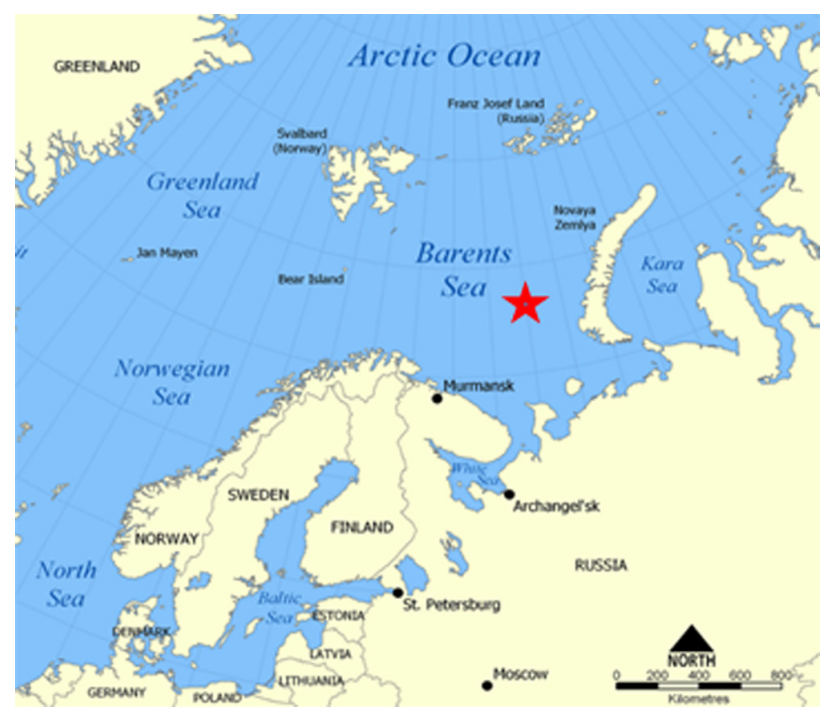

Fig. 1 Project site in Barents Sea (Wikipedia, 2019)

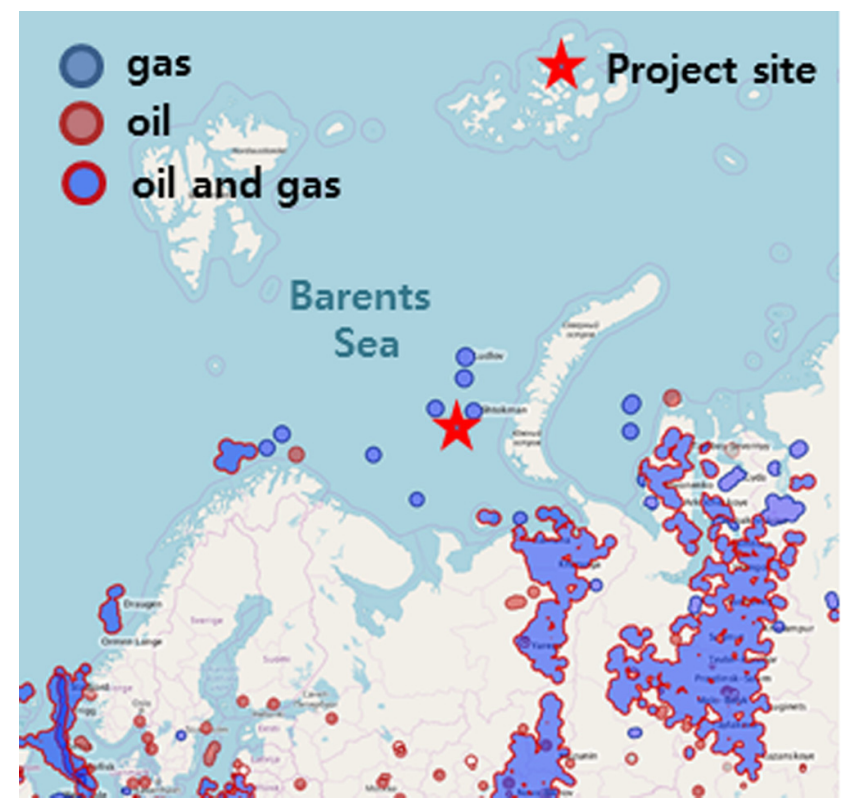

Fig. 2 Oil and gas filed in Barents Sea (WorldMap, n.d.) 


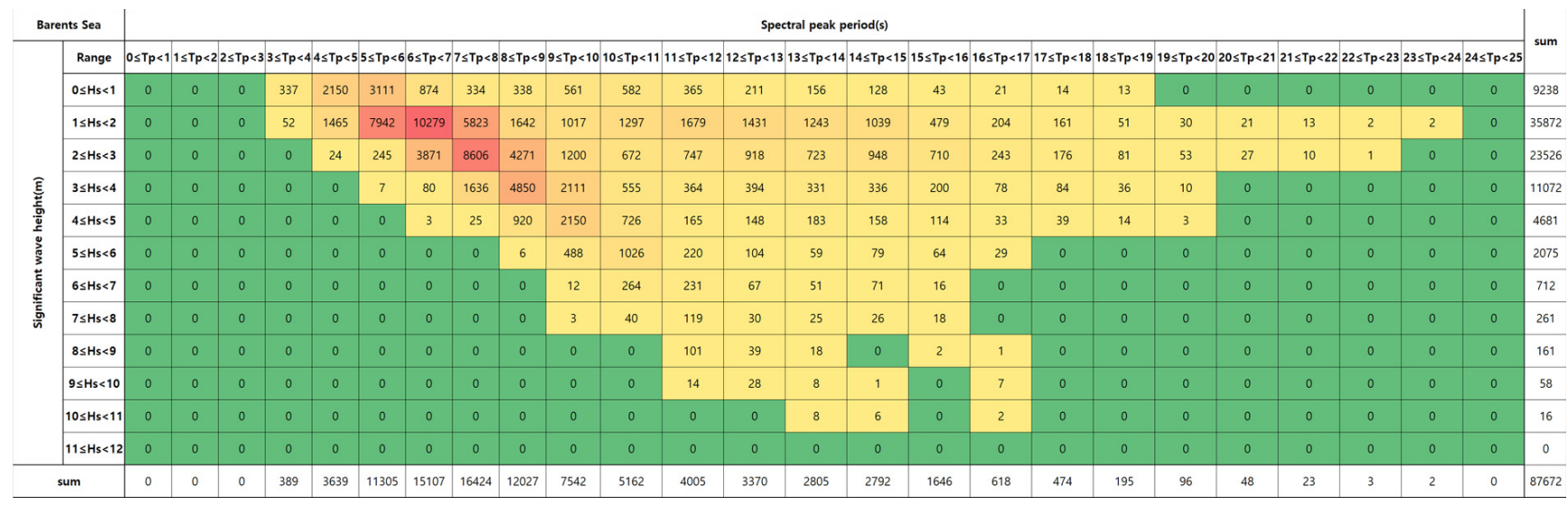

Fig. 3 Wave scatter diagram with $H s$ and $T p$
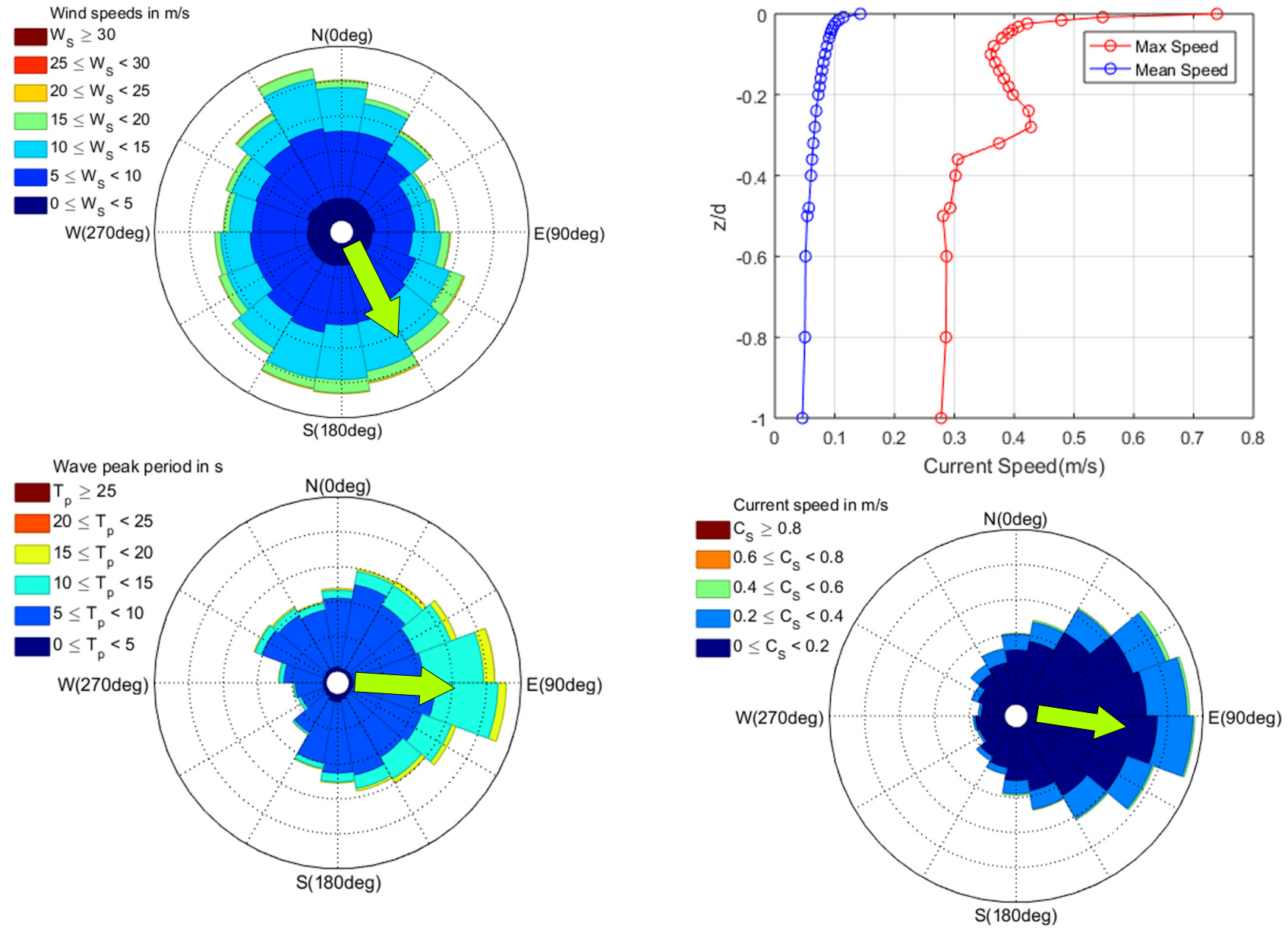

Fig. 4 Wave rose and wind rose

Fig. 5 Current profile and current rose at surface

The wave data showed the wave scatter diagram (WSD) for $H s$ and $T p$; the wave rose for the wave direction and $T p$, and the wind data showed that the wind rose for the wind direction and wind speed $\left(W_{s}\right)$ (Figs. 3 and 4). The current data represented the current increase for the current direction and current speed $(C s)$ at the surface and the current profile in the water depth direction (Fig. 5).

The WSD showed frequencies at $1 \mathrm{~m}$ intervals for $H s$ and at $1 \mathrm{~s}$ intervals for $T p$, and the total number of data was approximately 87,600 . The wave conditions with the highest frequencies in the project site were 1-2 $\mathrm{m}$ for $H s$ and 6-7 s for $T p$. The wave, wind, and current directions could be confirmed through the rose diagrams, and the directions were categorized into east $\left(90^{\circ}\right)$, south $\left(180^{\circ}\right)$, and west $\left(270^{\circ}\right)$ in the clockwise direction from the north direction $\left(0^{\circ}\right)$. In the case of the hindcast data purchased from Oceanweather Inc., the wave and current directions were defined as the directions to which the wave and current were moving, while the wind direction was defined as the direction from which the wind was coming. The wave and wind directions with the highest frequencies were East and North- 
Northwest (Fig. 4). Fig. 5 shows the current speed profile and direction in the water depth direction $(z)$. The current speed profile was nondimensionalized with the water depth of the project site $(d)$. The average and maximum current speeds were the fastest at the surface, and the dominant current direction at the surface was from the West to the East.

\section{Extreme Value Analysis}

For the extreme value analysis of metocean data, data collection, data selection, EVD selection, parameter estimation method selection, goodness-of-fit test, and return value derivation are required (Mathiesen et al., 1994). In this study, a global model that utilizes all of the collected metocean data was selected. In addition, the Gumbel distribution, two- and three-parameter Weibull distributions, and log-normal distribution were used as EVDs. The least-squares method was used to estimate the parameters of the EVDs. As the goodnessof-fit test, the K-S test that uses the maximum distance as a test statistic by comparing the cumulative distribution function (CDF) of metocean data with that of each EVD was used (Jeong et al., 2004; Jeong et al., 2008).

Eqs. (1)-(4) show the CDF of each EVD (Coles, 2001; Goda, 2000).

Gumbel distribution CDF:

$$
F(H s)=\exp \left\{-\exp \left[-\left(\frac{H s-\gamma}{\alpha}\right)\right]\right\}
$$

2-parameter Weibull distribution CDF:

$$
F(H s)=1-\exp \left[-\left(\frac{H s}{\alpha}\right)^{\beta}\right]
$$

3-parameter Weibull distribution CDF:

$$
F(H s)=1-\exp \left[-\left(\frac{H s-\gamma}{\alpha}\right)^{\beta}\right]
$$

$H s$ is the significant wave height; $\alpha, \beta$, and $\gamma$ are the scale parameter, shape parameter, and location parameter, respectively.

Log-normal distribution CDF:

$$
F(T p \mid H s)=\frac{1}{2}\left[1+\operatorname{erf}\left(\frac{\ln (T p-\mu)}{\sqrt{2} \sigma}\right)\right]=\Phi\left(\frac{(\ln (T p-\mu)}{\sigma}\right)
$$

$T p$ is the spectral peak wave period, and $\Phi$ is the CDF of the standard normal distribution (eq. (5)).

$$
\Phi(x)=\frac{1}{\sqrt{2 \pi}} \int_{-\infty}^{x} e^{-t^{2}} d t
$$

$\mu$ of the log-normal distribution can be expressed with the average value of $\ln (T p)$, as shown in Eq. (6); $\sigma$ can be expressed with the standard deviation of $\ln (T p)$, as shown in Eq. (7) (DNV, 2014).

$$
\begin{aligned}
& \mu=E[\ln T p]=a_{0}+a_{1} H s^{a_{2}} \\
& \sigma=s t d[\ln T p]=b_{0}+b_{1} e^{b_{2} H s}
\end{aligned}
$$

To estimate the parameters and coefficients $\left(a_{0}, a_{1}, a_{2}, b_{0}, b_{1}\right.$ and $\left.b_{2}\right)$ using the least-squares method, taking the $\log$ of both sides of each EVD, the log-normal distribution average equation, and the standard deviation equation followed by summarizing them into linear equations result in Eqs. (8)-(12).

Gumbel distribution:

$-\ln \left[-\ln (F(H s)]=\frac{1}{\alpha}(H s-\gamma)\right.$

2-parameter Weibull distribution:

$\ln [-\ln (F(H s))]=\beta \ln (H s)-\beta \ln \alpha$

3-parameter Weibull distribution:

$\ln [-\ln (F(H s))]=\beta \ln (H s-\gamma)-\beta \ln \alpha$

Log-normal distribution (mean):

$\ln \left(\mu-a_{0}\right)=\ln \left(a_{1}\right)+a_{2} \ln (H s)$

Log-normal distribution(standard deviation):

$\ln \left(\sigma-b_{0}\right)=\ln \left(b_{1}\right)+b_{2} H s$

For Eqs. (8) and (9), the least-squares method can be used directly. For Eq. (10), however, the parameters for which the $R^{2}$ value was closest to 1 were estimated, while the value of $\gamma$ was changed approximately 1,000 times within the range in which the value in the $\log$ was not negative. The $R^{2}$ value is the coefficient of determination that indicates the goodness-of-fit corresponding to the regression line. It approaches 1 as the samples used in statistical analysis exhibits smaller errors with the regression line.

Once the parameters are obtained through the least-squares method, the return values can be obtained using Eqs. (13)-(16).

Gumbel distribution:

$H s=-\alpha \ln [-\ln (F(H s)]+\gamma$

2-parameter Weibull distribution:

$H s=\alpha[-\ln (1-F(H s))]^{\frac{1}{\beta}}$

3-parameter Weibull distribution:

$H s=\alpha[-\ln (1-F(H s))]^{\frac{1}{\beta}}+\gamma$

Log-normal distribution CDF:

$T p=\exp \left[\sigma \Phi^{-1}\left(F_{T p \mid H s}(T p)\right)\right]+\mu$ 
After changing the variable from $H s$ to wind speed and current speed, their return values were derived using the same method as presented above.

\subsection{Extreme value analysis on wave and results}

$H s$ and $T p$, which are wave data, can be expressed by the conditional modeling approach, and the joint probability distribution of the two variables can be expressed as the product of the marginal probability distribution of $H_{s}$ and the conditional probability distribution of $T p$ for a given $H s$ (Orimolade et al., 2016; DNVGL, 2017).

In this study, the marginal probability distribution of $H s$ was assumed to be a Gumbel distribution and two- and three-parameter Weibull distributions using the WSD and the conditional probability distribution of $T p$, as the given $H s$ was assumed to be a log-normal distribution to calculate return values using the I-FORM method. Extreme value analysis was conducted after transforming the EVDs from the probability distribution function form to the CDF form for the convenience of calculation. The I-FORM method was proposed by Winterstein et al. (1993), and the data of Haver and Nyhus (1986) were used for the parameter estimation equations of the EVDs used. In other words, the I-FORM method calculates the exceedance probability in advance and obtains the corresponding response rapidly.

The procedure of the I-FORM method is expressed in Eqs. (17)-(24) (Haver and Winterstein, 2009).

$$
Q=1-F(H s, T p)=1 / N
$$

$Q$ is the exceedance probability. It is the reciprocal number of $N$, which is the total number of data.

$$
F(H s, T p)=\int f(H s, T p) d H s d T p=F(H s) F(T p \mid H s)
$$

where $F(H s)$ is the $\mathrm{CDF}$ of the marginal probability distribution, and $F(T p \mid H s)$ is the CDF of the conditional probability distribution

EVDs are moved to the space of the standard normal distributions of $u_{1}$ and $u_{2}$.

$$
\Phi\left(u_{1}\right)=F_{H s}(H s), \Phi\left(u_{2}\right)=F_{T p \mid H s}(T p)
$$

A circle equation with a radius of $B$ was introduced and represented by the relationship between the short-term period (Tss) an return period $(T r)$.

$$
\sqrt{u_{1}^{2}+u_{2}^{2}}=B=\Phi^{-1}\left(1-\frac{T s s}{365 \times 24 \times \operatorname{Tr}}\right)=\Phi^{-1}\left(1-\frac{1}{N}\right)
$$

where $B$ is the reliability index. One hour was used for $T s s, T r$ is the return period; 1,10 , and 100 years were used.

$$
u_{1 i}=B s_{i}, u_{2 i}= \pm \sqrt{B^{2}-u_{1 i}^{2}}
$$

$s_{i}$ in Eq. (21) is a dummy index, i.e., a number in the section between -1.0 and 1.0. Once $B$ is determined $H s$ and $T p$ can be obtained using the inverse function of each EVD (Eqs. (22)-(24)).

$$
\begin{aligned}
& H s_{i}=F_{H s}^{-1}\left(\Phi\left(u_{1 i}\right)\right) \\
& \mu_{i}=a_{0}+a_{1} H s_{i}^{a_{2}}, \sigma_{i}=b_{0}+b_{1} e^{b_{2} H s_{i}} \\
& T p_{i}^{ \pm}=F_{T p \mid H s}^{-1}\left(\Phi\left( \pm u_{2 i}\right)\right)
\end{aligned}
$$

The parameters of each EVD were estimated using the least- squares method, and the goodness-of-fit was tested using the K-S test. The parameters for which the $R^{2}$ value was the highest were extracted using MATLAB software (Figs. 6-7). The $R^{2}$ value was 0.99 , indicating that the numerical values agreed well with the actual values. The parameters were obtained using the slopes and y-intercept values (Tables 1-2).

To test the estimated parameters, the maximum distance difference between the CDF of the wave data and the CDF that included the parameters obtained by the least-squares method is shown in Fig. 8 . Based on the result of the K-S test, a test statistic $(D)$ value is presented. If this value is smaller than the threshold (Dcri) of 0.118 by the number of wave data at the significance level of $5 \%$, then the null
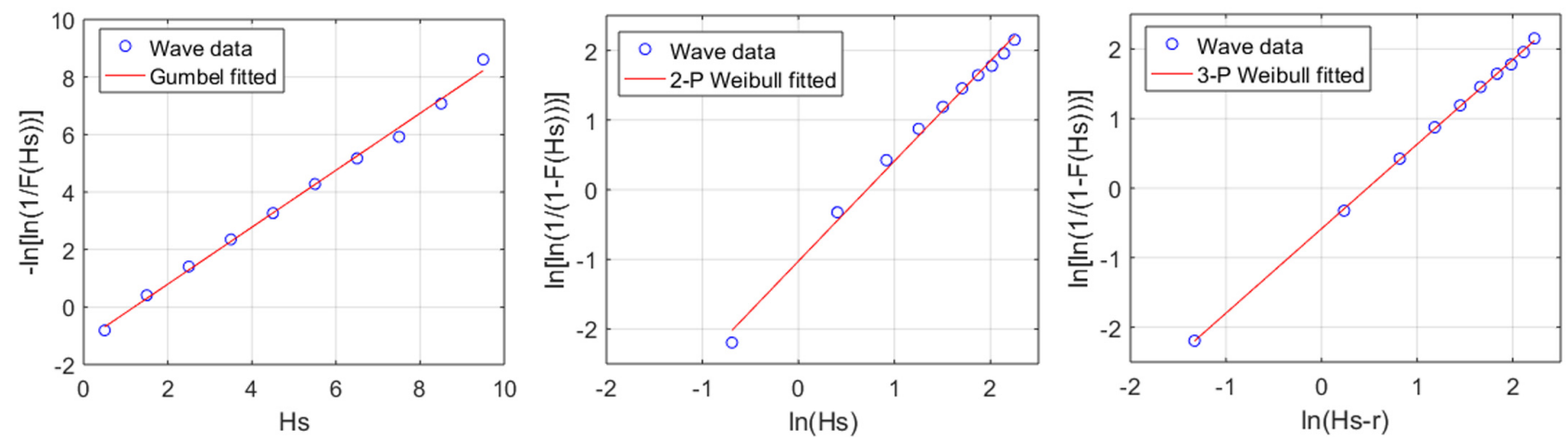

Fig. 6 Parameter estimation of extreme value distributions using least-squares method for significant wave height 

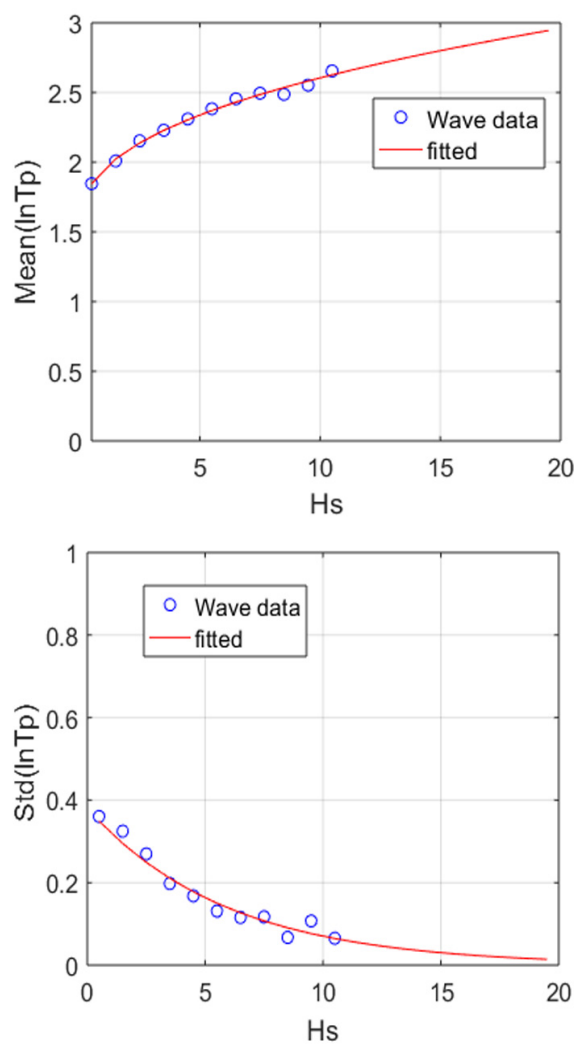

Fig. 7 Parameter estimation of log-normal distribution using least-squares method for spectral peak wave period

Table 1 Parameters of extreme value distributions for significant wave height

\begin{tabular}{cccc}
\hline Parameter & $\begin{array}{c}\text { Gumbel } \\
\text { distribution }\end{array}$ & $\begin{array}{c}\text { 2-parameter } \\
\text { Weibull } \\
\text { distribution }\end{array}$ & $\begin{array}{c}\text { 3-parameter } \\
\text { Weibull } \\
\text { distribution }\end{array}$ \\
\hline$\alpha$ (Scale) & 1.009 & 2.014 & 1.616 \\
$\beta$ (Shape) & - & 1.437 & 1.214 \\
$\gamma$ (Location) & 1.198 & 0 & 0.235 \\
$R^{2}$ & 0.996 & 0.994 & 0.999 \\
\hline
\end{tabular}

Table 2 Parameters of log-normal distribution

\begin{tabular}{cccc}
\hline $\begin{array}{c}\text { Parameter } \\
(a)\end{array}$ & $\begin{array}{c}\text { Log-normal } \\
\text { distribution }\end{array}$ & $\begin{array}{c}\text { Parameter } \\
(b)\end{array}$ & $\begin{array}{c}\text { Log-normal } \\
\text { distribution }\end{array}$ \\
\hline$a_{0}$ & 1.533 & $b_{0}$ & 0 \\
$a_{1}$ & 0.415 & $b_{1}$ & 0.380 \\
$a_{2}$ & 0.412 & $b_{2}$ & -0.169 \\
$R^{2}$ & 0.995 & $R^{2}$ & 0.923 \\
\hline
\end{tabular}

hypothesis that no difference exists between the two CDFs mentioned above can not be rejected (Kanji, 2006). In other words, it was discovered that the graphs of CDFs, including the parameters, agreed well with the actual data.

The contours for $H s$ and $T p$ were expressed using the I-FORM
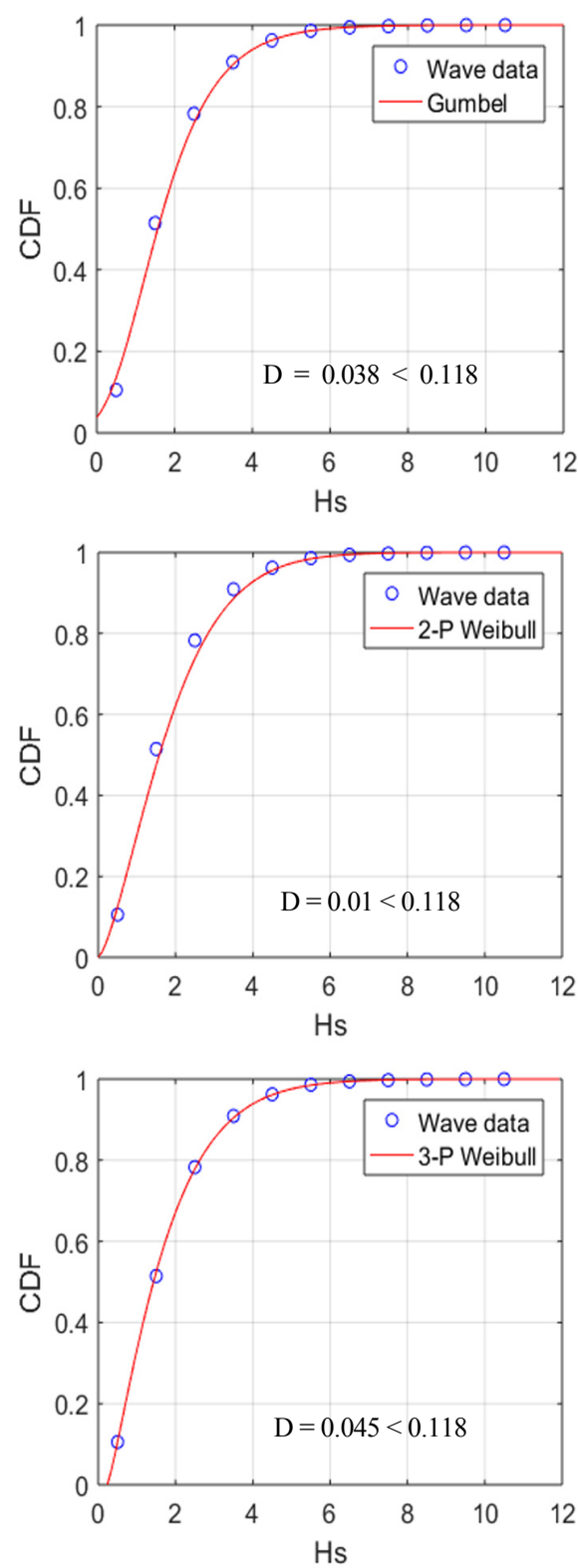

Fig. 8 Comparison between $\mathrm{CDF}$ of wave data and $\mathrm{CDF}$ of extreme value distribution

method of Eqs. (17)-(24), as shown in Fig. 9. The contours are shown for each return period (RP), and the return values corresponding to each return period are shown in Table 3.

When the 10-year hindcast data were compared with the 10-year return values, the highest prediction values could be obtained when the Gumbel distribution was assumed as the marginal probability distribution. The next highest values were derived by the threeparameter Weibull distribution, and two-parameter Weibull distribution exhibited the most similar results to those of the collected data. This was because the Gumbel distribution had a higher degree of scatter than the Weibull distribution. In addition, when the equations for obtaining the return values of the two- and three-parameter Weibull distributions were compared, it was discovered that different results were obtained depending on the value of the location parameter. 

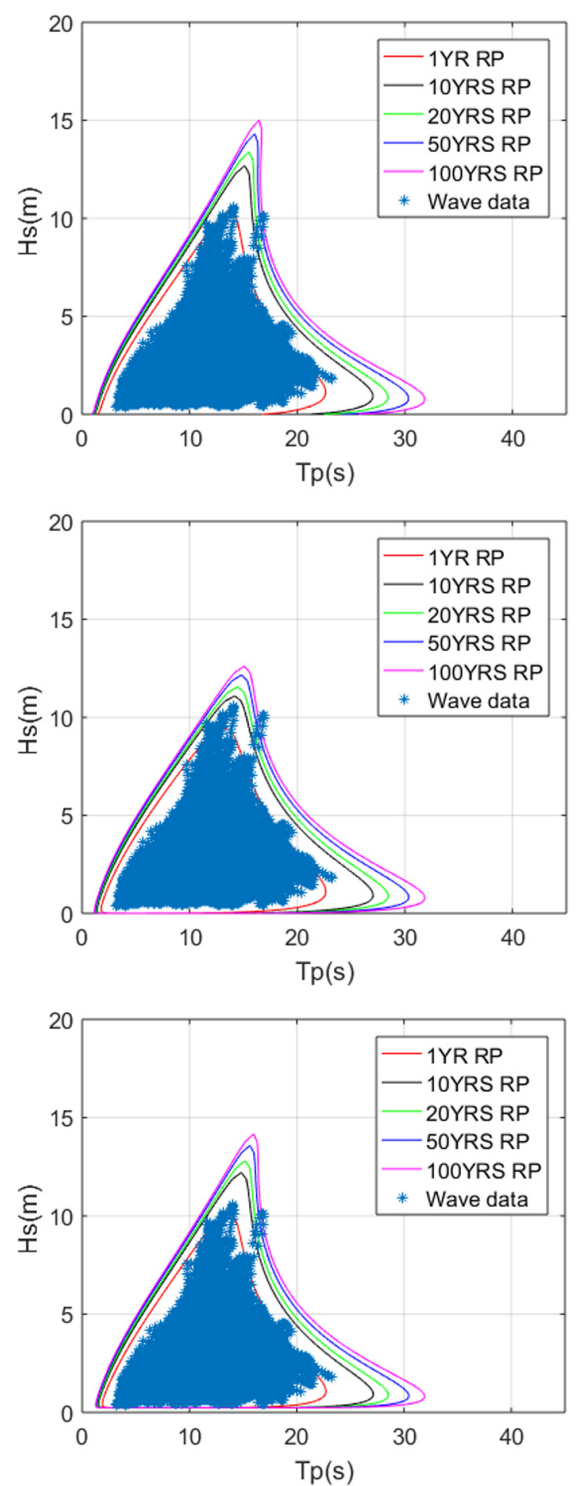

Fig. 9 Environmental contour for significant wave height and spectral peak wave period

Table 3 Return value for wave $(H s, T p)$

\begin{tabular}{ccccccc}
\hline \multirow{2}{*}{$\begin{array}{c}\text { Return } \\
\text { period } \\
\text { (yr, yrs) }\end{array}$} & \multicolumn{2}{c}{$\begin{array}{c}\text { Gumbel } \\
\text { distribution }\end{array}$} & \multicolumn{2}{c}{$\begin{array}{c}\text { 2-parameter } \\
\text { Weibull } \\
\text { distribution }\end{array}$} & \multicolumn{2}{c}{$\begin{array}{c}\text { 3-parameter } \\
\text { Weibull } \\
\text { distribution }\end{array}$} \\
\cline { 2 - 8 } & $\begin{array}{c}H s \\
(\mathrm{~m})\end{array}$ & $\begin{array}{c}T p \\
(\mathrm{~s})\end{array}$ & $\begin{array}{c}H s \\
(\mathrm{~m})\end{array}$ & $\begin{array}{c}T p \\
(\mathrm{~s})\end{array}$ & $\begin{array}{c}H s \\
(\mathrm{~m})\end{array}$ & $\begin{array}{c}T p \\
(\mathrm{~s})\end{array}$ \\
\hline 1 & 10.36 & 13.75 & 9.48 & 13.22 & 10.17 & 13.64 \\
10 & 12.68 & 15.11 & 11.09 & 14.18 & 12.21 & 14.83 \\
20 & 13.38 & 15.52 & 11.56 & 14.45 & 12.80 & 15.18 \\
50 & 14.31 & 16.05 & 12.16 & 14.81 & 13.59 & 15.63 \\
100 & 15.01 & 16.45 & 12.61 & 15.07 & 14.17 & 15.97 \\
\hline
\end{tabular}

\subsection{Extreme value analysis on wind and current and results}

The wind speed $(W s)$ was distributed within the $0-27 \mathrm{~m} / \mathrm{s}$ range and the total number of data was approximately 87,600 . The CDF was obtained at $2 \mathrm{~m} / \mathrm{s}$ intervals. The current speed $(C s)$ ranged from
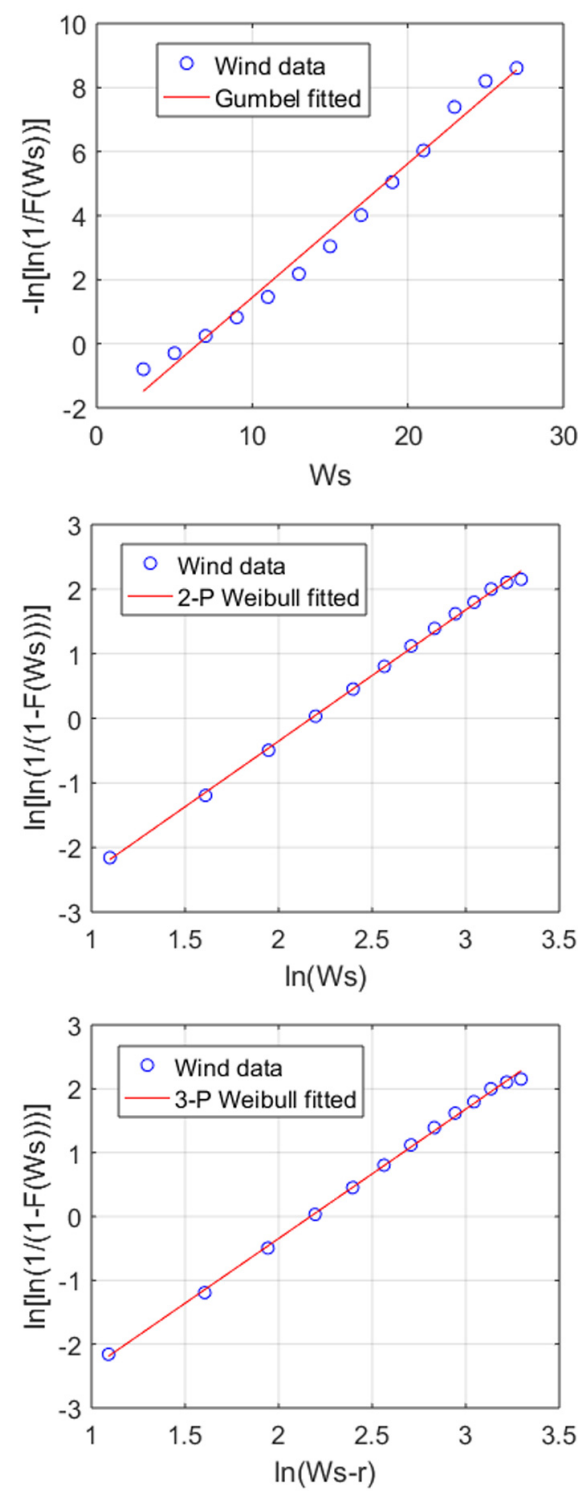

Fig. 10 Parameter estimation of extreme value distributions using least square method for wind speed

Table 4 Parameters of extreme value distribution for wind speed

\begin{tabular}{cccc}
\hline Parameter & $\begin{array}{c}\text { Gumbel } \\
\text { distribution }\end{array}$ & $\begin{array}{c}\text { 2-parameter } \\
\text { Weibull } \\
\text { distribution }\end{array}$ & $\begin{array}{c}\text { 3-parameter } \\
\text { Weibull } \\
\text { distribution }\end{array}$ \\
\hline$\alpha$ & 2.392 & 8.790 & 8.763 \\
$\beta$ & - & 2.033 & 2.028 \\
$\gamma$ & 6.543 & 0 & 0.022 \\
$R^{2}$ & 0.987 & 0.999 & 0.999 \\
\hline
\end{tabular}

0 to $70 \mathrm{~cm} / \mathrm{s}$ and the total number of data was 7,200. The CDF was obtained at $5 \mathrm{~cm} / \mathrm{s}$ intervals. To derive the return values for the $W s$ and $C s$, which were single variables, the Gumbel distribution and two- and three-parameter Weibull distributions were used as EVDs, and the least-squares method was used for parameter estimation (Figs. 10 and 12). The parameters were obtained using the slopes and y-intercept values when the $R^{2}$ value was the highest (Tables 4 and 6). The K-S 

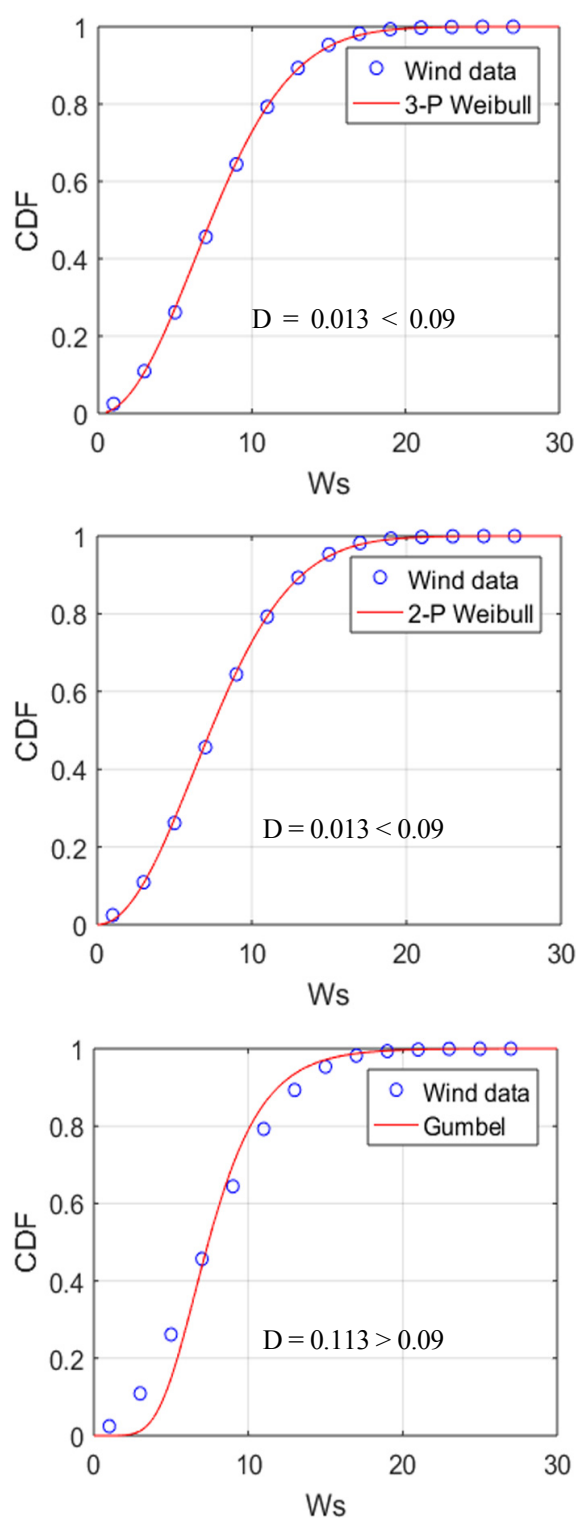

Fig. 11 Comparison between $\mathrm{CDF}$ of wind data and $\mathrm{CDF}$ of extreme value distributions

Table 5 Return value for wind speed

\begin{tabular}{cccc}
\hline \multirow{2}{*}{$\begin{array}{c}\text { Return period } \\
\text { (yr, yrs) }\end{array}$} & $\begin{array}{c}\text { Gumbel } \\
\text { distribution }\end{array}$ & $\begin{array}{c}\text { 2-parameter } \\
\text { Weibull } \\
\text { distribution }\end{array}$ & $\begin{array}{c}\text { 3-parameter } \\
\text { Weibull } \\
\text { distribution }\end{array}$ \\
\cline { 2 - 4 } 1 & \multicolumn{3}{c}{ Wind speed $(W s)(\mathrm{m} / \mathrm{s})$} \\
\hline 10 & 28.26 & 26.01 & 26.03 \\
20 & 33.77 & 29.07 & 29.10 \\
50 & 35.43 & 29.93 & 29.96 \\
100 & 39.62 & 31.03 & 31.06 \\
\hline
\end{tabular}

test was used to test the parameters, and test statistic $(D)$ values are presented as results (Figs. 11 and 13). If these values are smaller than the threshold (Dcri) of 0.09 by the number of wind and current data at
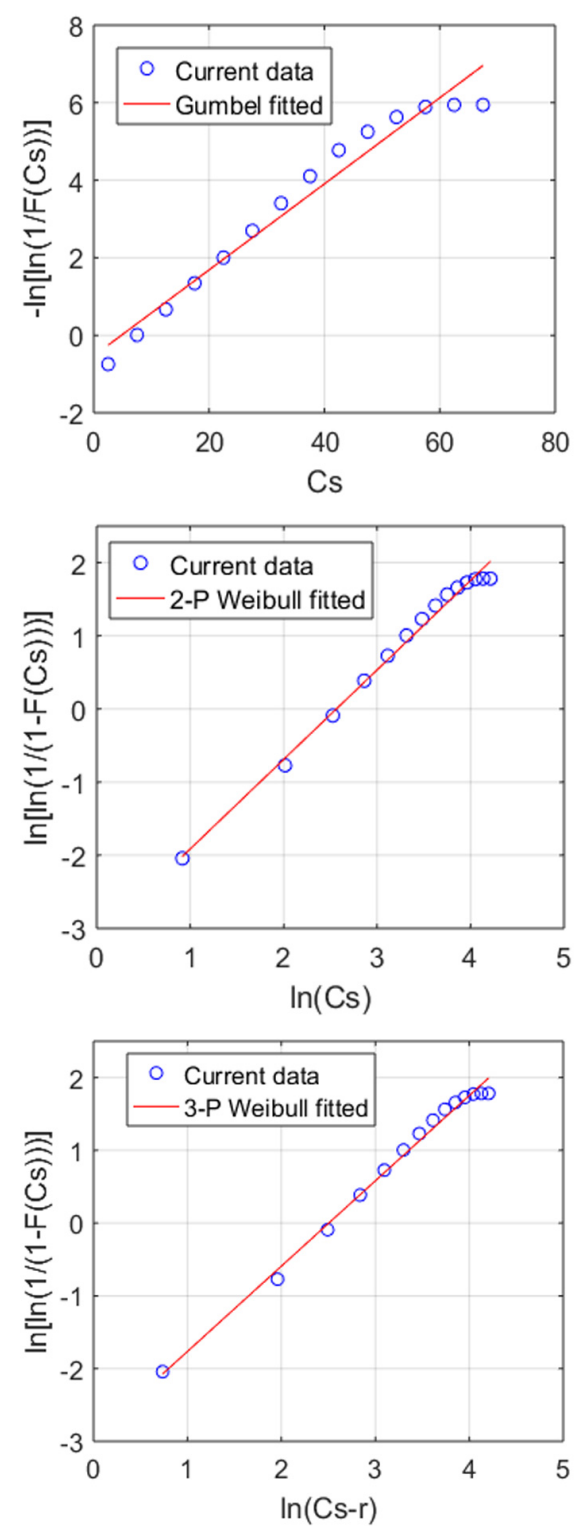

Fig. 12 Parameter estimation of extreme value distributions using least square method for current speed at surface

Table 6 Parameters of extreme value distribution for current speed at surface

\begin{tabular}{cccc}
\hline Parameter & $\begin{array}{c}\text { Gumbel } \\
\text { distribution }\end{array}$ & $\begin{array}{c}\text { 2-parameter } \\
\text { Weibull } \\
\text { distribution }\end{array}$ & $\begin{array}{c}\text { 3-parameter } \\
\text { Weibull } \\
\text { distribution }\end{array}$ \\
\hline$\alpha$ & 9.010 & 12.986 & 12.235 \\
$\beta$ & - & 1.224 & 1.173 \\
$\gamma$ & 4.800 & 0 & 0.414 \\
$R^{2}$ & 0.963 & 0.992 & 0.992 \\
\hline
\end{tabular}

the significance level of $5 \%$, then the null hypothesis cannot be rejected. In other words, it was discovered that the graphs of the CDFs, including the parameters, agreed well with the actual data. The return values for the $W s$ and $C s$ were calculated using a method similar to the analysis of the wave data (Tables 5 and 7). 

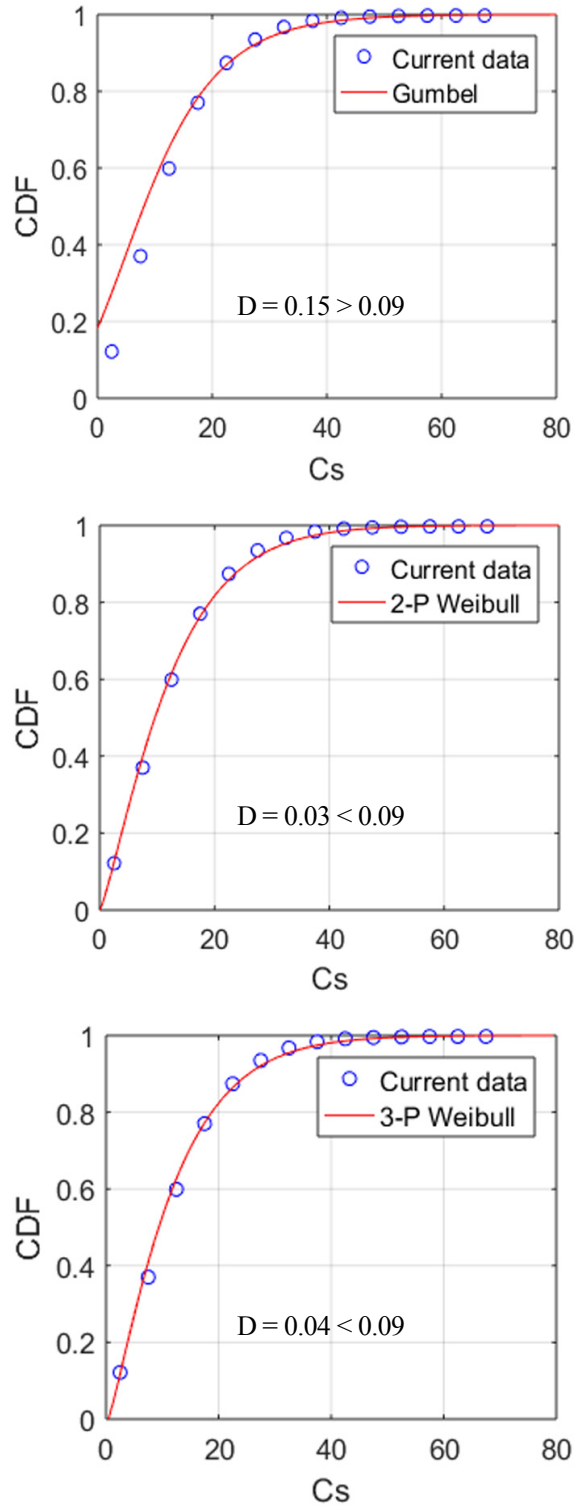

Fig. 13 Comparison between $\mathrm{CDF}$ of current data at surface and $\mathrm{CDF}$ of extreme value distributions

Table 7 Return value for current speed at surface

\begin{tabular}{cccc}
\hline \multirow{2}{*}{$\begin{array}{c}\text { Return period } \\
\text { (yr, yrs) }\end{array}$} & $\begin{array}{c}\text { Gumbel } \\
\text { distribution }\end{array}$ & $\begin{array}{c}\text { 2-parameter } \\
\text { Weibull } \\
\text { distribution }\end{array}$ & $\begin{array}{c}\text { 3-parameter } \\
\text { Weibull } \\
\text { distribution }\end{array}$ \\
\cline { 2 - 4 } & \multicolumn{3}{c}{ Current speed $(C s)(\mathrm{cm} / \mathrm{s})$} \\
\hline 1 & 57.95 & 55.38 & 56.01 \\
10 & 78.70 & 72.49 & 74.05 \\
20 & 84.95 & 77.46 & 79.32 \\
50 & 93.20 & 83.92 & 86.20 \\
100 & 99.45 & 88.73 & 91.35 \\
\hline
\end{tabular}

As for the overall tendency of the return values for the $W s$ and Cs, the Gumbel distribution exhibited the highest prediction values, similarly to the results of the wave data, followed by the three- and two-parameter Weibull distributions. When the maximum $W s$ and $C s$ of the 10-year hindcast data $(27 \mathrm{~m} / \mathrm{s}$ and $70 \mathrm{~cm} / \mathrm{s}$, respectively) were compared with the 10-year return values of the two-parameter Weibull distribution $(29.07 \mathrm{~m} / \mathrm{s}$ and $72.49 \mathrm{~cm} / \mathrm{s}$, respectively) large differences of $7.6 \%$ and $3.5 \%$ were discovered, respectively.

The prediction values of the Gumbel distribution were the highest because the null hypothesis was rejected as the test statistic was higher than the threshold in the K-S test results; hence, overestimated results were obtained. This was because the intervals determined to calculate the ranges and frequencies of the $W s$ and $C s$ were larger compared to the wave data; hence, errors were accumulated when the parameters were calculated using the least-squares method. The reclassification of data through the independent and identically distributed (IID) verification of changes in the intervals for extracting the frequencies of the $W s$ and $C s$ is expected to further improve the accuracy (Choi et al., 2019).

\section{Conclusion}

In this study, an extreme value analysis for the $H s, T p$, wind speed, and current speed was conducted using the hindcast metocean data of the Barents Sea in the Arctic region to derive return values required for the design of offshore structures. In the extreme value analysis for the $H s$ and $T p$, the marginal probability distribution of the $H_{s}$ was assumed to be a Gumbel distribution and two- and three-parameter Weibull distributions, and the conditional probability distribution of the $T p$ for the given $H s$ was assumed to be a log-normal distribution to calculate return values using the I-FORM method. For the $W s$ and $C s$, which were single variables, return values were calculated through the Gumbel distribution and two- and three-parameter Weibull distributions. The parameters were estimated using the least-squares method and tested through the K-S test.

The return values for the $H s, T p$, and wind speed for the 100-year return period and those for current speed for the 10-year return period, which are required for the design of general offshore structures were summarized (as shown in Table 8). As the degree of scatter of metocean data increased, the differences in return values between the Gumbel and Weibull distributions increased. The Weibull distribution should be used for widely distributed metocean data, such as wind speed and current speed data.

The results of this study can be used as the metocean data design values of offshore structures to be installed in the Barents Sea;

Table 8 Extreme value for metocean data with

\begin{tabular}{|c|c|c|c|}
\hline \multicolumn{2}{|c|}{ Metocean data } & Return period & Return value \\
\hline \multirow[b]{2}{*}{ Wave } & $H_{s}(\mathrm{~m})$ & \multirow{2}{*}{$100(\mathrm{yrs})$} & $12.61 \sim 15.01$ \\
\hline & $T p(\mathrm{~s})$ & & $15.07 \sim 16.45$ \\
\hline \multicolumn{2}{|c|}{ Wind speed $(\mathrm{m} / \mathrm{s})$} & $100(\mathrm{yrs})$ & $31.83 \sim 39.28$ \\
\hline \multicolumn{2}{|c|}{ Current speed at surface $(\mathrm{cm} / \mathrm{s})$} & 10 (yrs) & $72.49 \sim 78.70$ \\
\hline
\end{tabular}


furthermore, they can be utilized as basic data for offshore structure motion and mooring analyses, structural analyses, and air gap calculations. In the future, the method of estimating parameters will be extended from the least-squares method to the moment area and maximum likelihood methods. In addition, in the case of widely distributed metocean data, such as $W s$ and $C s$ data, they will be reclassified through an IID verification to select appropriate intervals.

\section{Acknowlegement}

This work was supported by the Technology Innovation Programs of "Development of Arctic Ocean-Based Floating Offshore Structure Geometry Capable of Year-Round Operation Under ARC7 Condition by Applying Position Maintenance and Mooring Systems (Project No.: 10063405)," "Construction of Equipment for Assessing the Performance of Hydrogen Fuel Cell ESS Systems for MW-Class Vessels and Test Method Development (Project No.: 20006636)," and the "South Korea-U.K. Offshore Plant Global Professional Training Program (Project No.: 0001288)", which were funded by the Ministry of Trade, Industry, and Energy of the Republic of Korea.

\section{References}

API (American Petroleum Institute). (2005). Design and Analysis of Station keeping Systems for Floating Structures. API RP-2SK 3rd Edition.

Bird, K.J., Charpentier, R.R., Gautier, D.L., Houseknecht, D.W., Klett, T.R., Pitman, J.K., ... Wandrey, C.R. (2008). CircumArctic Resource Appraisal: Estimates of Undiscovered Oil and Gas North of the Arctic Circle (No. 2008-3049). US Geological Survey. https://doi.org/10.3133/fs20083049

BV (Bureau Veritas). (2015). Classification of Mooring Systems for Permanent and Mobile Offshore Units. BV Rule Note NR 493 DT R03 E.

Choi, Y.H. (2016). Extreme Value Analysis of Environmental Data. Proceedings of the Fall Conference of the Korean Society of Ocean Engineers, Busan, Korea, 181-186.

Choi, Y.H, Yeon, S.M., Kim, H., \& Lee, D. (2019). Extreme Value Analysis of Statistically Independent Stochastic Variables. Journal of Ocean Engineering and Technology, 33(3), 222-228. https://doi.org/10.26748/KSOE.2018.093

Coles, S. (2001). An Introduction to Statistical Modeling of Extreme Values. Springer Texts in Statistics, London: Springer. https://doi.org/10.1007/978-1-4471-3675-0

DNVGL. (2017). Environmental Conditions and Environmental Loads. DNV-RP-C205.

DNVGL (Det Norske Veritas and Germanischer Lloyd). (2015). Position Mooring. DNV-OS-E301.
DNV (Det Norske Veritas). (2014). Environmental Conditions and Environmental Loads. DNV-RP-C205.

Goda, Y. (2000). Random Seas and Design of Maritime Structures (2nd ed.). Singapore: World Scientific Publishing Company.

Haver, S., \& Nyhus, K.A. (1986). A Wave Climate Description for Long Term Response Calculations. Proceedings of 5th International OMAE Symposium, Tokyo, 4, 27-34.

Haver, S., \& Winterstein, S.R. (2009). Environmental Contour Lines: A Method for Estimating Long Term Extremes by a Short Term Analysis. Transactions of the Society of Naval Architects and Marine Engineers, 116, 116-127.

Jeong, S.T., Kim, J.D., Ko, D.H., \& Yoon, G.L. (2008). Parameter Estimation and Analysis of Extreme Highest Tide Level in Marginal Seas around Korea. Journal of Korean Society of Coastal and Ocean Engineers, 20(5), 482-490.

Jeong, S.T., Kim, J.D., \& Cho, H.Y. (2004). Characteristics on the Extreme Value Distributions of Deepwater Design Wave Heights off the Korean Coast. Journal of Korean Society of Coastal and Ocean Engineers, 16(3), 130-141.

Kanji, G.K. (2006). 100 Statistical Tests. SAGE.

Ko, D.H., Jeong, S.T., Cho, H.Y., \& Kang, K.S. (2014). Extreme Offshore Wind Estimation using Typhoon Simulation. Journal of Korean Society of Coastal and Ocean Engineers, 26(1), 16-24. https://doi.org/10.9765/KSCOE.2014.26.1.16

Mathiesen, M., Goda, Y., Hawkes, P.J., Mansard, E., Martín, M.J., Peltier, E., ... Van Vledder, G. (1994). Recommended Practice for Extreme Wave Analysis. Journal of hydraulic Research, 32(6), 803-814. https://doi.org/10.1080/00221689409498691

National Oceanic and Atmospheric Administration (NOAA). (2018). Arctic Report Card 2018.

Orimolade, A.P., Haver, S., \& Gudmestad, O.T. (2016). Estimation of Extreme Significant Wave Heights and the Associated Uncertainties: A Case Study using NORA10 Hindcast Data for the Barents Sea. Marine Structures, 49, 1-17. https://doi. org/10.1016/j.marstruc.2016.05.004

Van Os, J., Caires, S., \& Van Gent, M. (2011). Guidelines for Metocean Data Analysis. Proceedings of the 21st International Offshore and Polar Engineering Conference, International Society of Offshore and Polar Engineers.

Winterstein, S.R., Ude, T.C., Cornell, C.A., Bjerager, P., \& Haver, S. (1993). Environmental Parameters for Extreme Response: Inverse FORM with Omission Factors. Proceedings of the 6th International Conference on Structural Safety and Reliability (ICOSSAR-93), Innsbruck, Austria, 551-557.

Wikipedia. (2019). Barents Sea. Retrieved August 2019 from https://en.wikipedia.org/wiki/Barents_Sea

WorldMap. (n.d.). Oil \& Gas Map. Retrieved August 2019 from https://worldmap.harvard.edu/maps/6718 


\section{Author ORCIDs and Contributions}

\begin{tabular}{|c|c|c|}
\hline Author name & ORCID & Contributions \\
\hline Park, Sung Boo & 0000-0001-9587-2183 & (1)(2)(3) \\
\hline Shin, Seong Yun & 0000-0001-6665-9092 & (3) \\
\hline Shin, Da Gyun & 0000-0002-3976-1961 & (2) \\
\hline Jung, Kwang Hyo & 0000-0002-8229-6655 & (5) \\
\hline Choi, Yong Ho & 0000-0002-6653-5476 & (3) \\
\hline Lee, Jae Yong & 0000-0002-4469-7765 & (2) \\
\hline Lee, Seung Jae & 0000-0001-8992-6915 & (2) \\
\hline \multicolumn{3}{|c|}{ (1) Conceived of the presented idea or developed the theory } \\
\hline \multicolumn{3}{|c|}{ (2) Carried out the experiment or collected the data } \\
\hline \multicolumn{3}{|c|}{ (3) Performed the analytic calculations or numerical simulations } \\
\hline \multicolumn{3}{|c|}{ (4) Wrote the manuscript } \\
\hline \multicolumn{3}{|c|}{ (5) Supervised the findings of this study } \\
\hline
\end{tabular}

